Purdue University Purdue e-Pubs

6-11-2019

\title{
The Identification of Minimum Weight Sound Packages That Meet Specified Vehicle Interior Sound Pressure Levels
}

Hyunjun Shin

Purdue University, shin20@purdue.edu

J Stuart Bolton

Purdue University, bolton@purdue.edu

Follow this and additional works at: https://docs.lib.purdue.edu/herrick

Shin, Hyunjun and Bolton, J Stuart, "The Identification of Minimum Weight Sound Packages That Meet Specified Vehicle Interior Sound Pressure Levels" (2019). Publications of the Ray W. Herrick Laboratories. Paper 198.

https://docs.lib.purdue.edu/herrick/198

This document has been made available through Purdue e-Pubs, a service of the Purdue University Libraries. Please contact epubs@purdue.edu for additional information. 


\section{NOISE AND VIBRATION} CONFERENCE \& EXHIBITION

THE IDENTIFICATION OF MINIMUM WEIGHT SOUND PACKAGES THAT MEET SPECIFIED VEHICLE INTERIOR SOUND PRESSURE LEVELS

(SAE Technical Paper 2019-01-1504)

Hyunjun Shin, J. Stuart Bolton

Ray W. Herrick Laboratories, Purdue University, West Lafayette, IN, USA

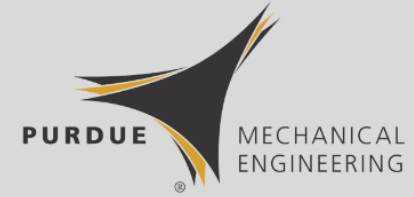


- Minimize The Weight Of A Sound Package By Balancing Absorption And Transmission Performance

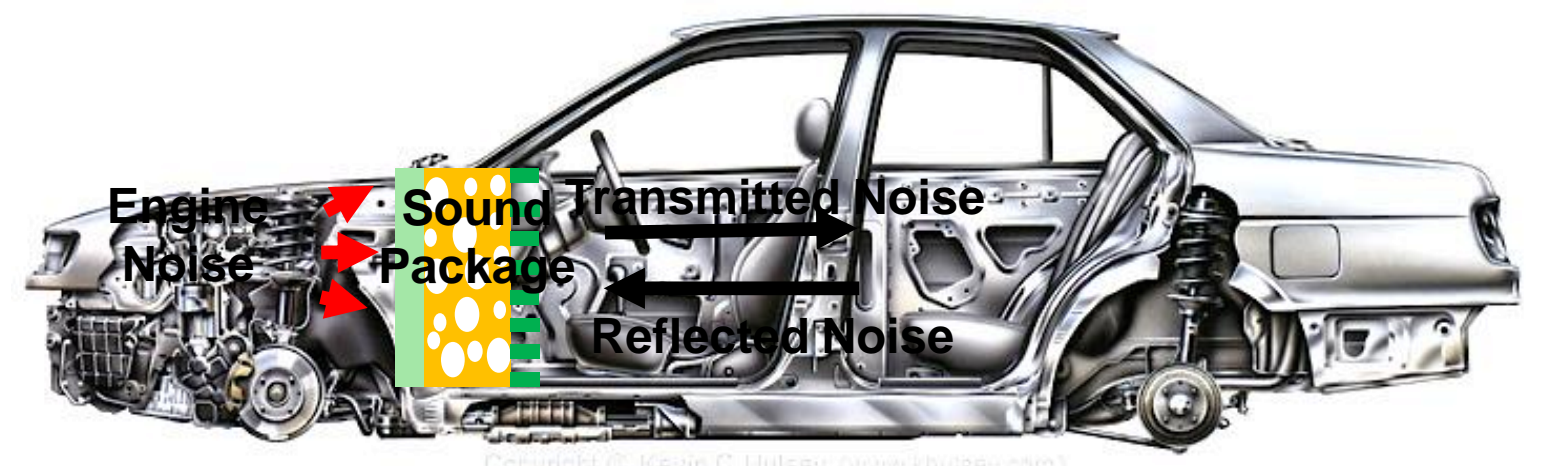

- Impact Of A Weight Optimization Of The Sound Package In The Automotive Industry

Total weight reduction $\rightarrow$ Improve gas mileage (Battery mileage) beyond current levels Conventional sound package for a luxury vehicle $\rightarrow$ about 120 lbs 


\section{PREVIOUS WORK}

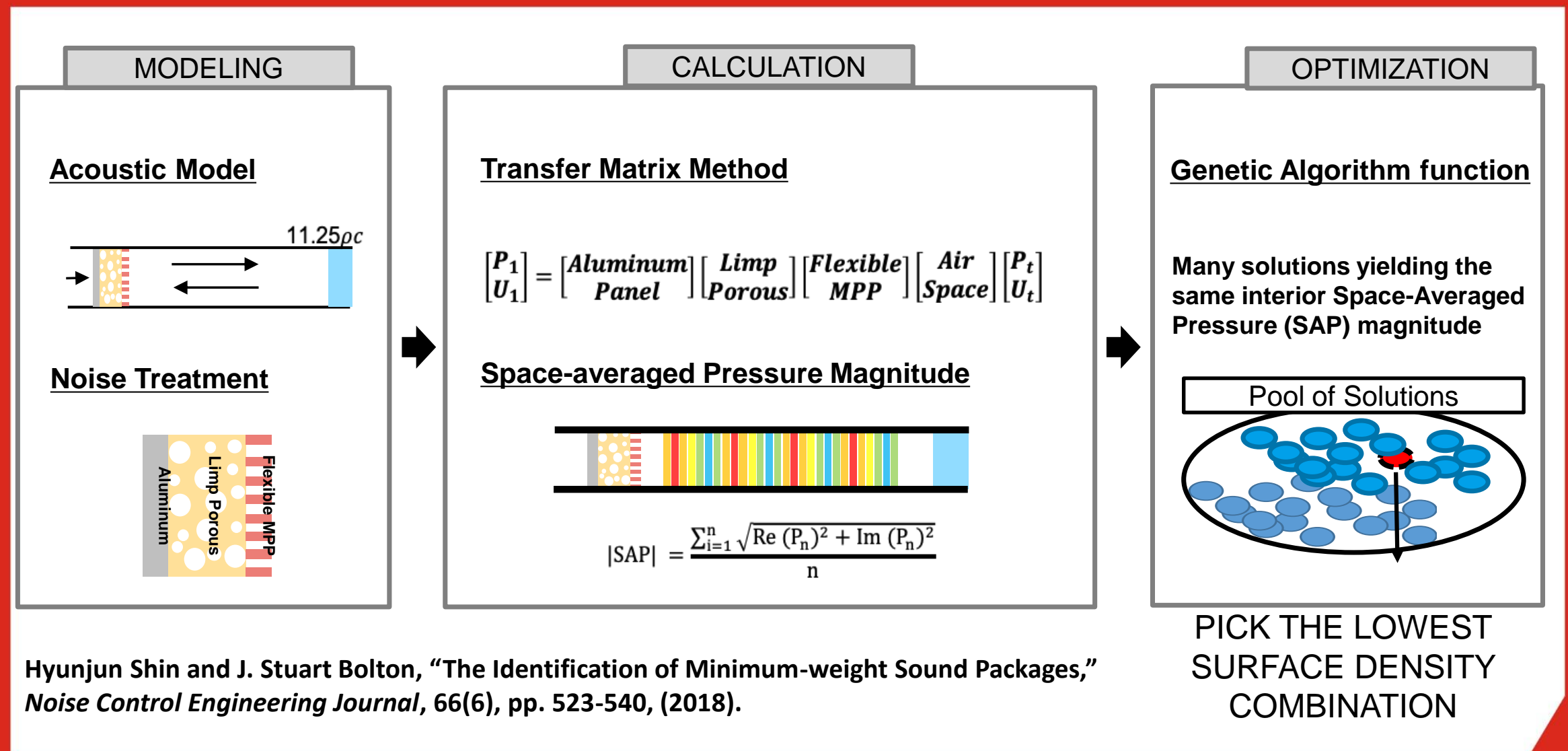




\section{INTRODUCTION}

\section{SOUND PACKAGE LAYOUT}

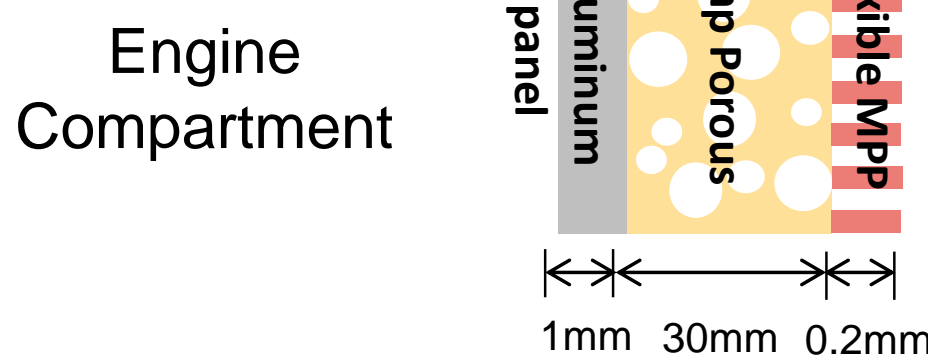

\section{SAP CALCULATION}

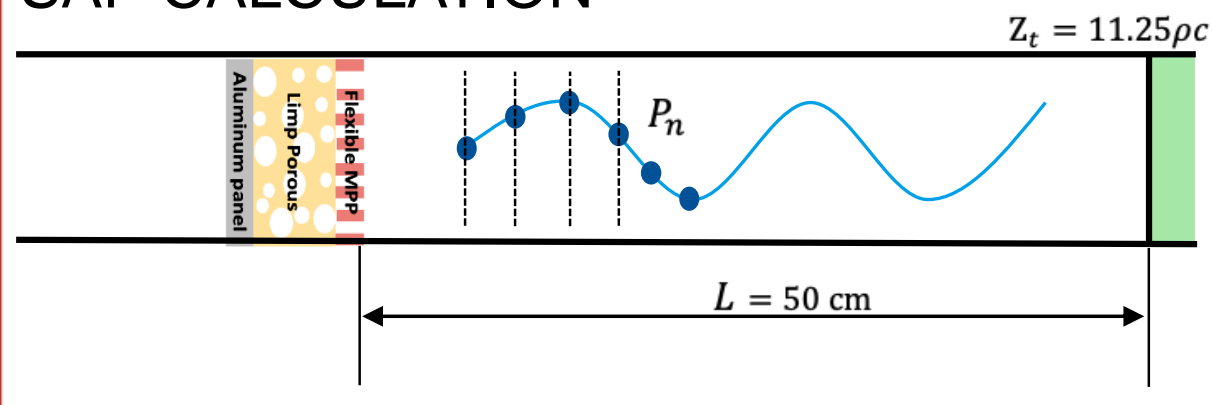

Vehicle Interior 


\section{OPTIMIZATION PROCESS}

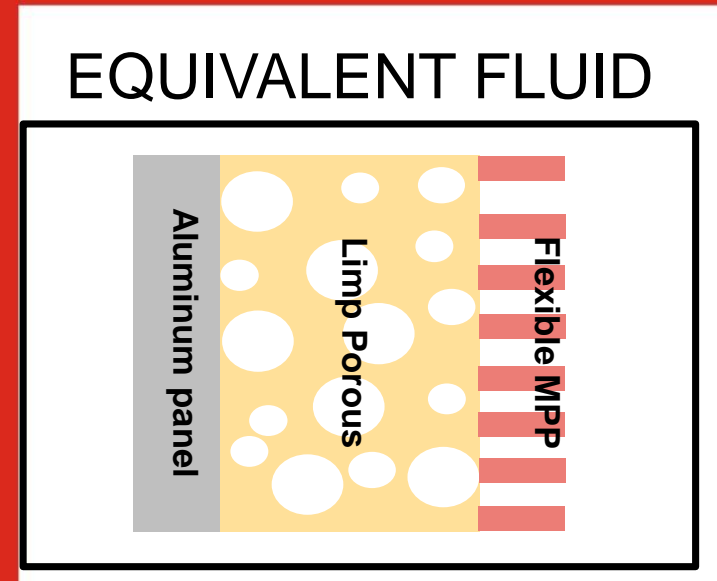

\section{SELECTION}

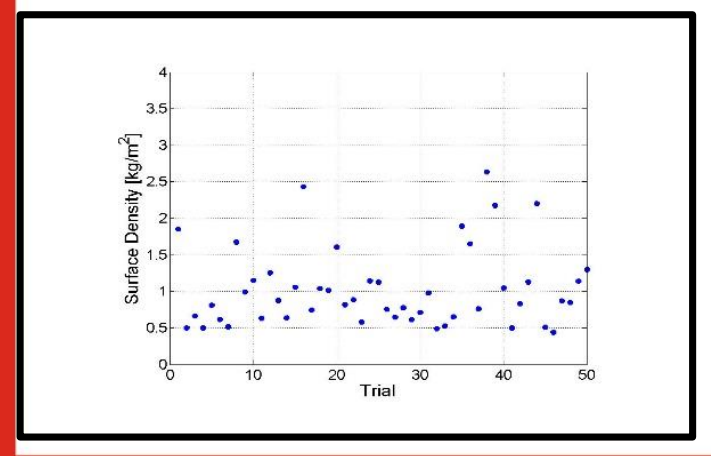

SAE INTERNATIONAL
SAP CALCULATON

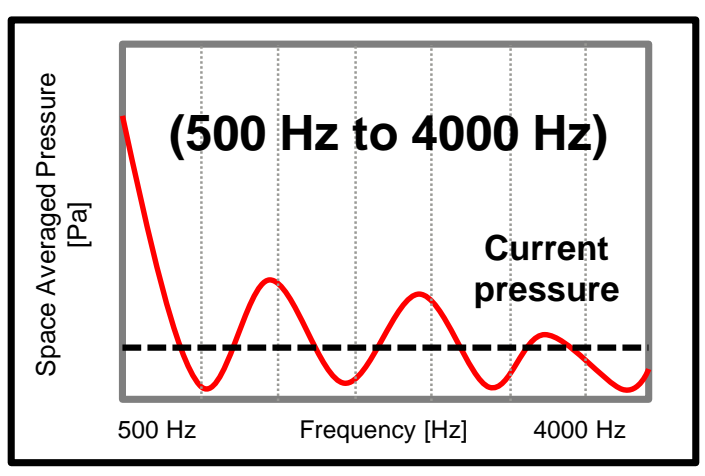

GA OPTIMIZER

Flexible MPP

$$
\begin{aligned}
& \sigma_{\text {low }} \leq \sigma_{M P P} \leq \sigma_{u p} \\
& m_{\text {low }} \leq m_{M P P} \leq m_{\text {up }}
\end{aligned}
$$

Limp porous Layer

$\sigma_{\text {low }} \leq \sigma_{\text {porous }} \leq \sigma_{\text {up }}$

$m_{\text {low }} \leq m_{\text {porous }} \leq m_{\text {up }}$
TARGET SAP

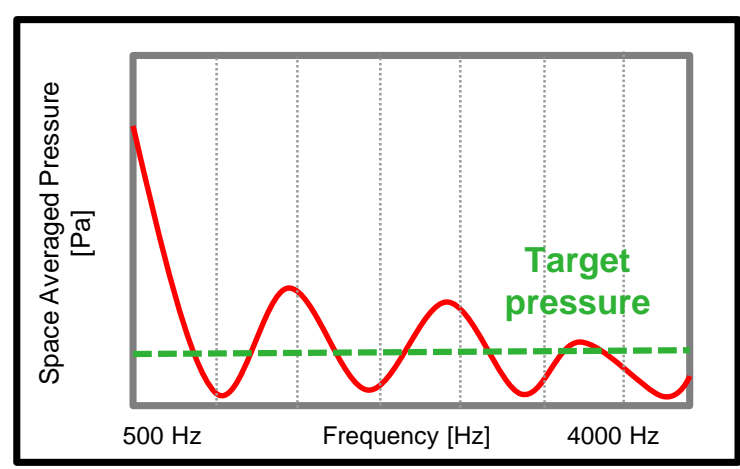

Error Function

$$
E=\left|1-\frac{\boldsymbol{S A P}_{\text {Current }}}{\boldsymbol{S A P}_{\text {Target }}}\right|
$$




\section{OPTIMIZATION RESULTS}

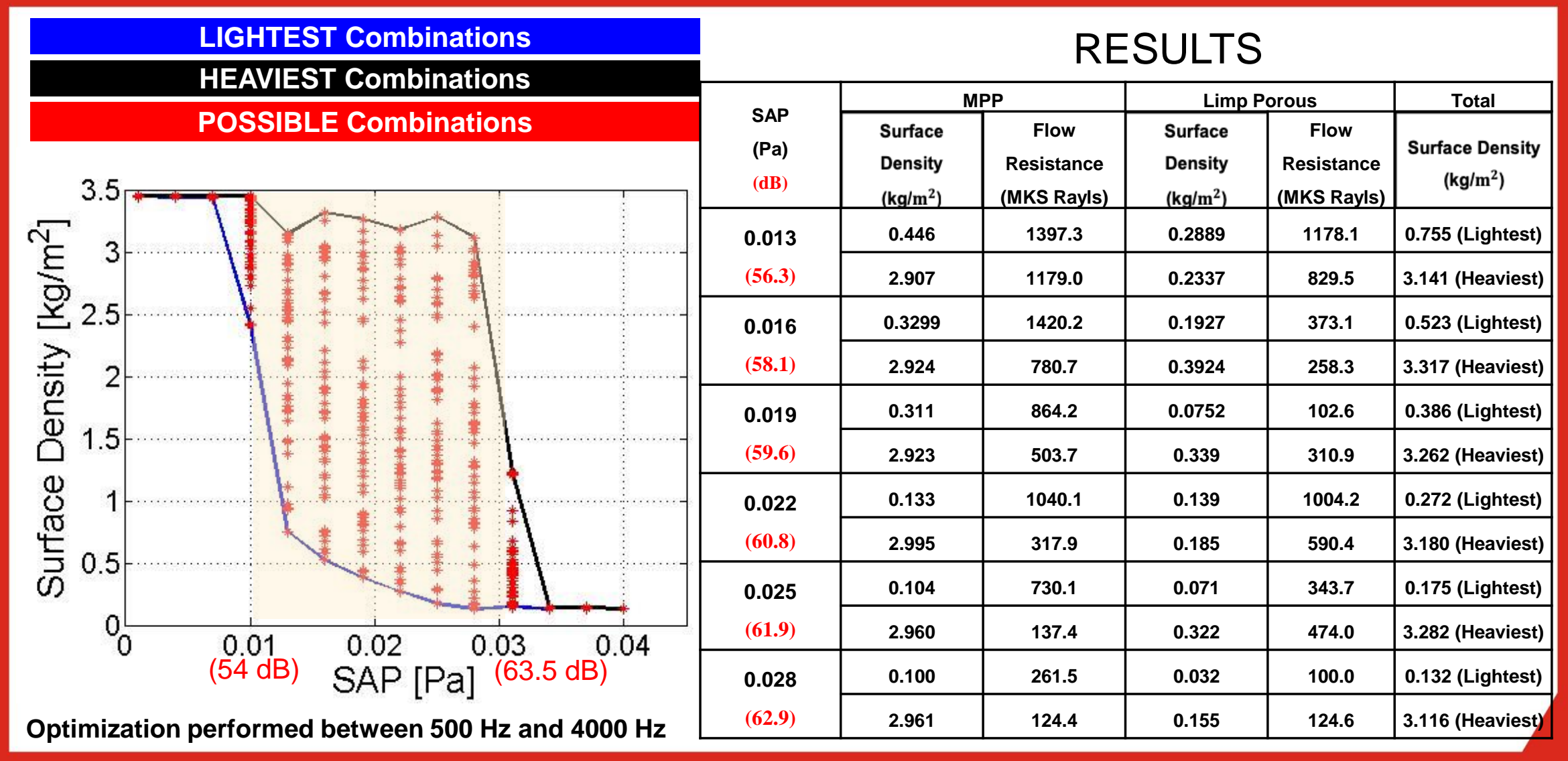


- It was found that when the sound package consisted of an aluminum panel, and a layer of fibrous material with a microperforated panel surface treatment, the lightest solutions tended to favor barrier performance over absorption performance, and that the majority of the mass and flow resistance tended to be given to the microperforated panel

- It was found that the total surface density required to meet a target sound pressure increased rapidly as the target level decreased, thus suggesting that the shape of the target spectrum should be designed carefully so that weight is not "spent" creating very low sound pressure levels in frequency bands that are not important from a sound quality point-of-view 


\section{EFFECT OF BASE PANEL MASS}

\section{Aluminum to Steel Panel}

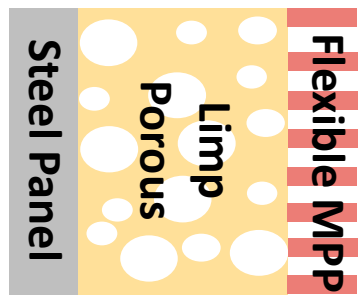

Results

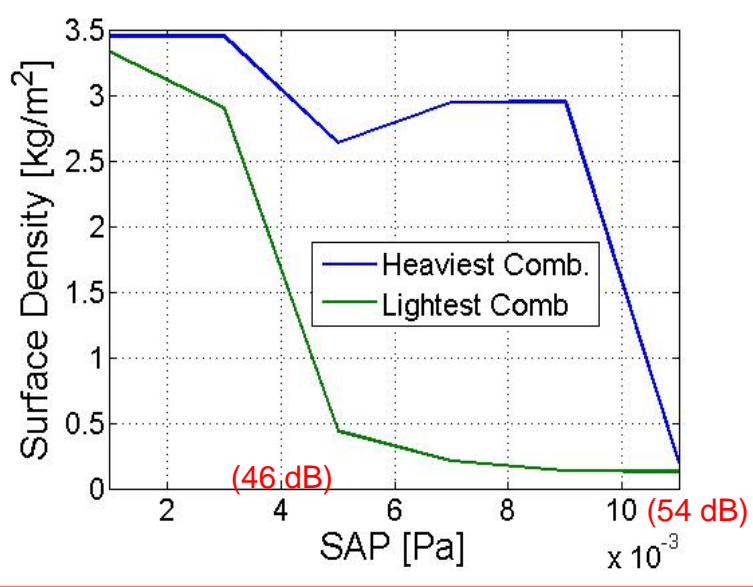




\section{EFFECT OF FREQUENCY A-WEIGHTING}

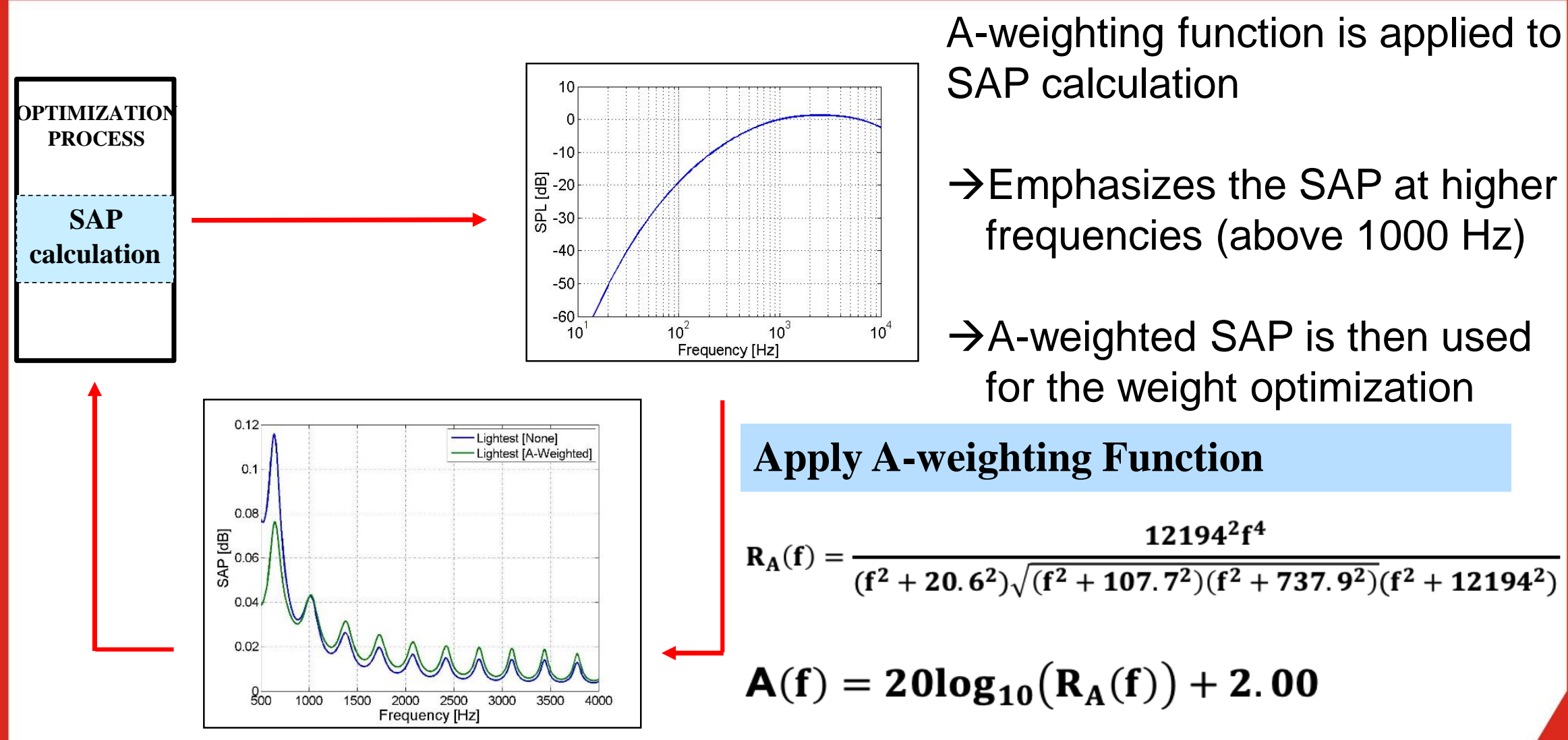




\section{EFFECT OF FREQUENCY A-WEIGHTING}

\section{A-weighting case}

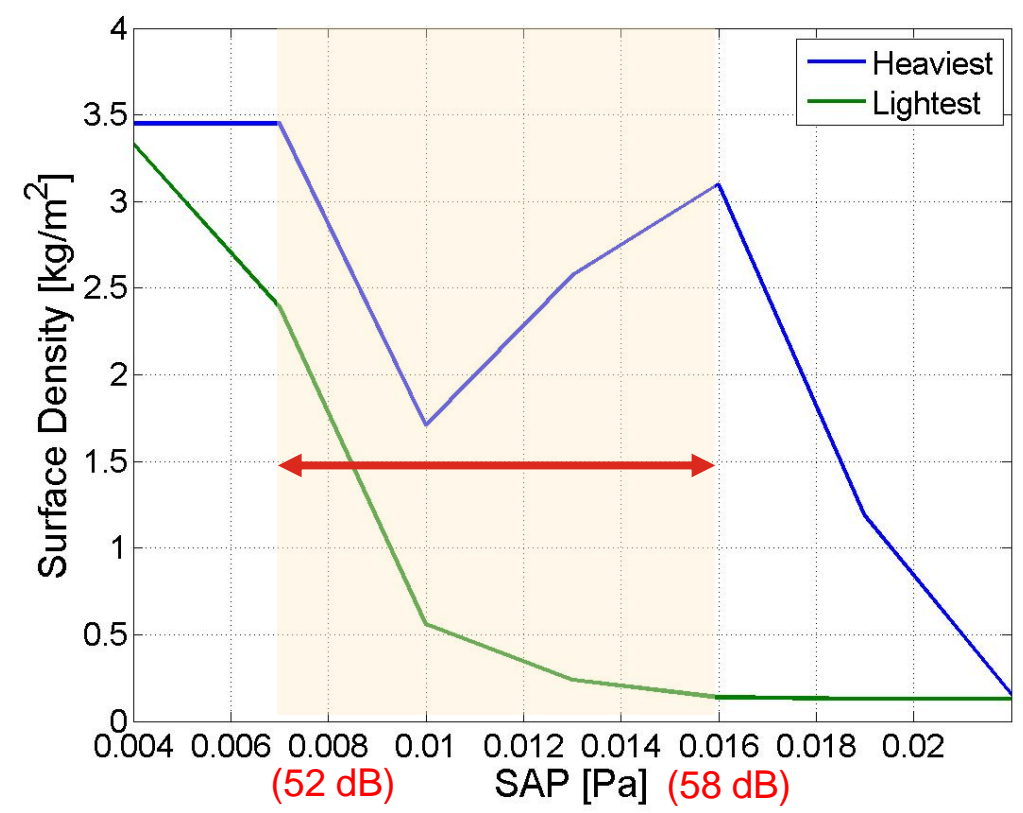

\begin{tabular}{|c|c|c|c|c|c|}
\hline \multirow{2}{*}{$\begin{array}{l}\text { SAP } \\
(\mathbf{P a}) \\
(\mathrm{dB})\end{array}$} & & & & & \\
\hline & $\begin{array}{l}\text { Surface } \\
\text { Density } \\
\left(\mathrm{kg} / \mathrm{m}^{2}\right)\end{array}$ & $\begin{array}{c}\text { Flow } \\
\text { Resistance } \\
\text { (MKS Rayls) }\end{array}$ & $\begin{array}{l}\text { Surface } \\
\text { Density } \\
\left(\mathrm{kg} / \mathrm{m}^{2}\right)\end{array}$ & $\begin{array}{c}\text { Flow } \\
\text { Resistance } \\
\text { (MKS Rayls) }\end{array}$ & $\begin{array}{l}\text { Surface } \\
\text { Density } \\
\left(\mathrm{kg} / \mathrm{m}^{2}\right)\end{array}$ \\
\hline \multirow{2}{*}{$\begin{array}{l}0.007 \\
(50.9)\end{array}$} & 1.943 & 1464.4 & 0.449 & 1493.3 & $\begin{array}{c}2.392 \\
\text { (Lightest) }\end{array}$ \\
\hline & 2.999 & 1438.8 & 0.451 & 1018.6 & $\begin{array}{c}\mathbf{3 . 4 5 0} \\
\text { (Heaviest) }\end{array}$ \\
\hline \multirow{2}{*}{$\begin{array}{c}0.01 \\
(53.9)\end{array}$} & 0.407 & 1288.6 & 0.142 & 1388.5 & $\begin{array}{c}\mathbf{0 . 5 5 9} \\
\text { (Lightest) }\end{array}$ \\
\hline & 1.639 & 1067.7 & 0.070 & 248.7 & $\begin{array}{c}1.709 \\
\text { (Heaviest) }\end{array}$ \\
\hline \multirow{2}{*}{$\begin{array}{l}0.013 \\
(56.3)\end{array}$} & 0.125 & 1011.9 & 0.114 & 1138.7 & $\begin{array}{c}0.239 \\
\text { (Lightest) }\end{array}$ \\
\hline & 2.239 & 140.2 & 0.336 & 140.2 & $\begin{array}{c}2.575 \\
\text { (Heaviest) }\end{array}$ \\
\hline \multirow{2}{*}{$\begin{array}{l}0.016 \\
(58.1)\end{array}$} & 0.100 & 104.0 & 0.375 & 144.5 & $\begin{array}{c}\mathbf{0 . 1 3 7 5} \\
\text { (Lightest) }\end{array}$ \\
\hline & 2.955 & 385.8 & 0.145 & 100.0 & $\begin{array}{c}3.100 \\
\text { (Heaviest) }\end{array}$ \\
\hline
\end{tabular}

Optimization performed between $100 \mathrm{~Hz}$ and $10000 \mathrm{~Hz}$ 


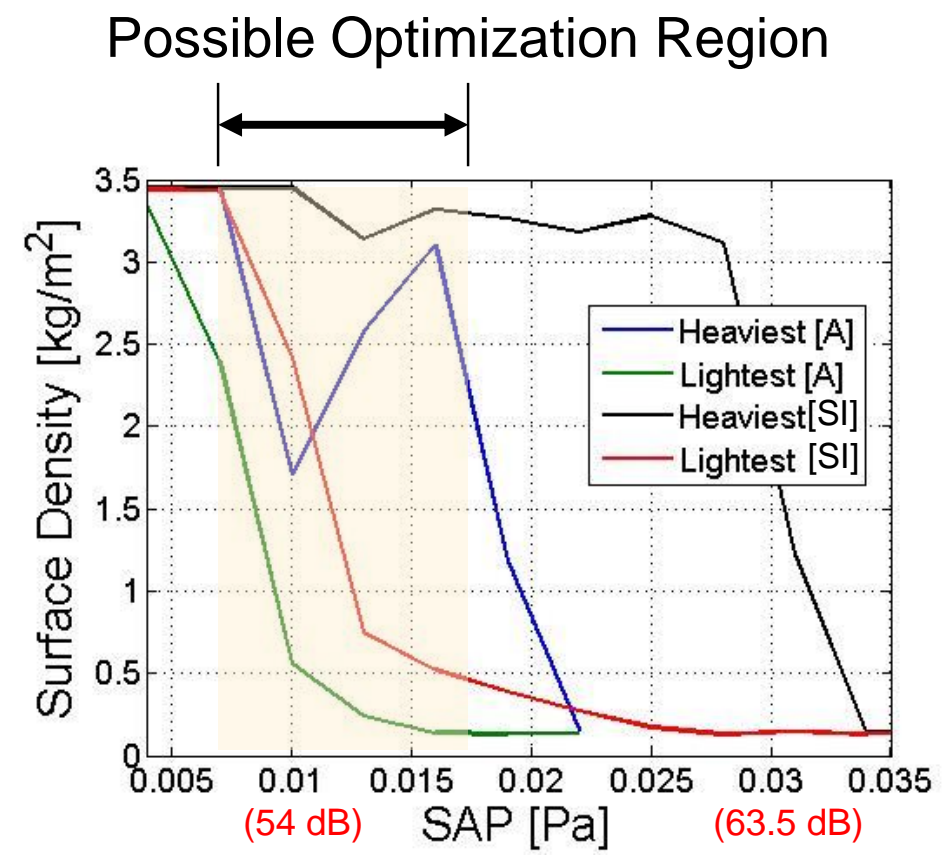

\section{Lightest possible combinations}

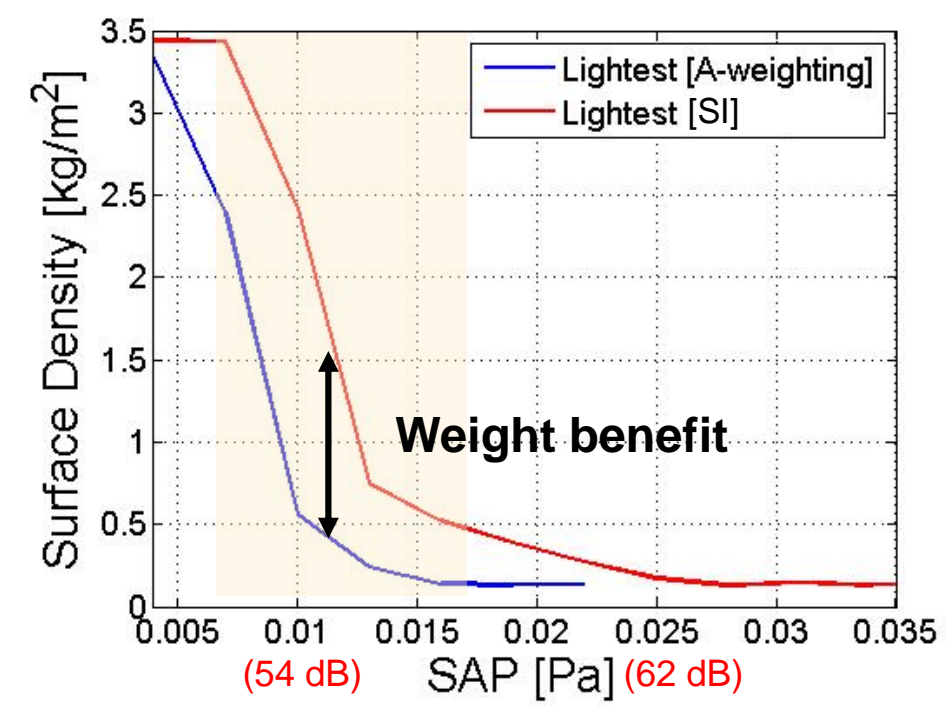

- A-weighting optimization $\rightarrow$ Lighter solutions 


\section{OBSERVATIONS}

- Light base panel - barrier performance is emphasized at the expense of absorption

- Heavier base panel - absorption performance is emphasized because of improved barrier performance of base panel

- A-weighted target spectrum reduces mass required to meet target

- Target spectrum has a large impact on surface density

- Large weight penalty if target levels too low: i.e., target "good" level, not "best possible" level 


\section{FE MODEL OF MORE REALISTIC INTERIOR}

- More realistic case which describes the vehicle interior volume.

- For the passenger vehicle

$\rightarrow$ Head room

: $1000 \mathrm{~mm}$ to $1100 \mathrm{~mm}$

$\rightarrow$ Leg room

: $1000 \mathrm{~mm}$ to $1100 \mathrm{~mm}$

$\rightarrow$ Second Leg room

: $800 \mathrm{~mm}$ to $1000 \mathrm{~mm}$

$\rightarrow$ Front of the car to the rear seat

: $1800 \mathrm{~mm}$ to $2100 \mathrm{~mm}$
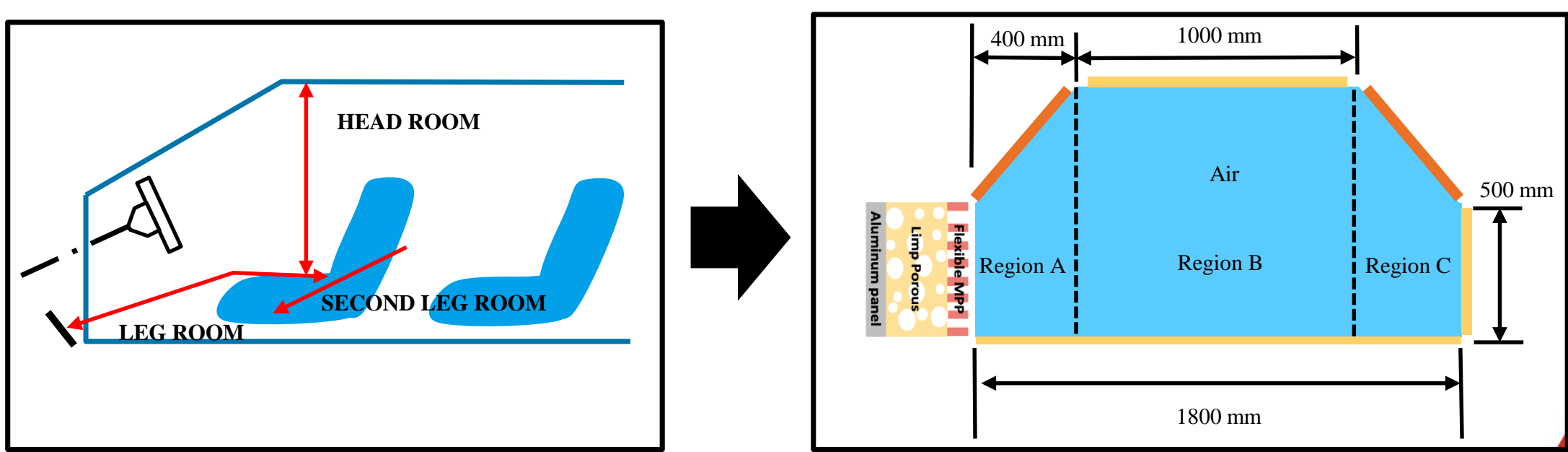
- Use of FE model in optimization procedure is prohibitively expensive compared to TMM/duct model

- Would be useful to perform optimization using TMM-duct model and relate those results to the levels in a more realistic interior geometry: i.e., translate target level in realistic geometry to target level in simple duct geometry 


\section{CORRELATION BETWEEN A SIMPLE DUCT AND A REALISTIC MODEL}

To make the a averaged absorption in the downstream section 0.3

Averaged Absorption Calculation

$$
\overline{\alpha_{\text {Total }}}=\frac{\sum S_{i} A_{i}}{S} \quad \begin{aligned}
& S \text { denotes the total surface area } \\
& \begin{array}{l}
S_{i} \text { describes an area of each surfaces } \\
\alpha_{\text {Total }} \text { denotes the total absorption of the surface } \\
A_{i} \text { denotes the absorption of each surface }
\end{array}
\end{aligned}
$$

\begin{tabular}{l|l|l|l|l|l|l}
\hline SAP [dB] Duct & 56.3 & 58.1 & 59.6 & 60.8 & 61.9 & 62.9 \\
\hline SAP [dB] VLC & 51.7 & 53.6 & 55.1 & 56.4 & 57.5 & 58.4 \\
\hline
\end{tabular}

SAP for both cases are calculated and plotted

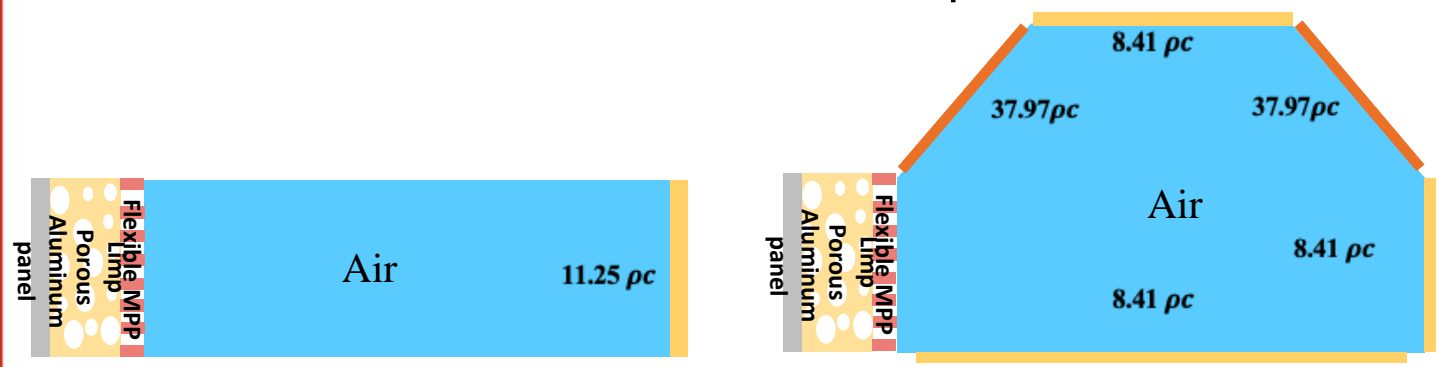

SAP [VLC] vs. SAP [Duct]

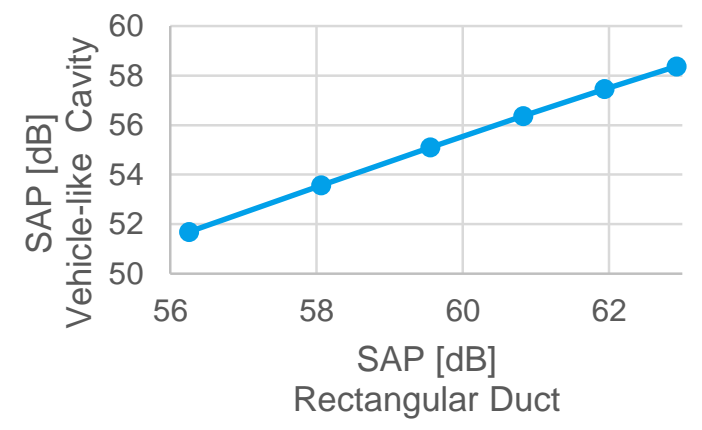

- SAPs of 10 different surface density combinations (A set of 10 lowest surface densities that gave the same SAP)

- Clear relation between SAP's in the two geometries 


\section{EMPIRICAL EQUATION DEVELOPMENT PROCESS}

\section{DATA COLLECTION}

\section{Straight Duct Case}

Various SAP target \& Absorption

- Sound Energy Density In The Cavity

- Sound Power Incident At Inlet

- Space-averaged Pressure In The Cavity

\section{VLC Case}

Various SAP target \& Absorption

- Sound Energy Density In The Cavity

- Sound Power Incident At Inlet

- Space-averaged Pressure In The Cavity

\section{FIND CORRELATION}

\section{Acoustic Properties}

Various SAP targets \& Absorption

- Sound Energy Density Ratio

$$
\frac{E_{\text {Duct }} / A_{\text {Duct }}}{E_{\mathrm{VLC}} / A_{\mathrm{VLC}}}
$$

- Space-Averaged Pressure Ratio

$$
\frac{\text { SAP }_{\text {Duct }}}{\text { SAP }_{\text {VLC }}}
$$

- Sound Power Incident Ratio [VLC Only]

$$
\frac{\mathrm{P}_{\mathrm{VLC}}}{\mathrm{P}_{\mathrm{In}, \mathrm{VLC}}}
$$

- Sound Power incident Ratio

$$
\mathrm{P}_{\text {In,Duct }} / \mathrm{A}_{\text {In,Duct }}
$$$$
\mathrm{P}_{\text {In,VLC/A }} \text { In,VLC }
$$

\section{DEVELOPMENT}

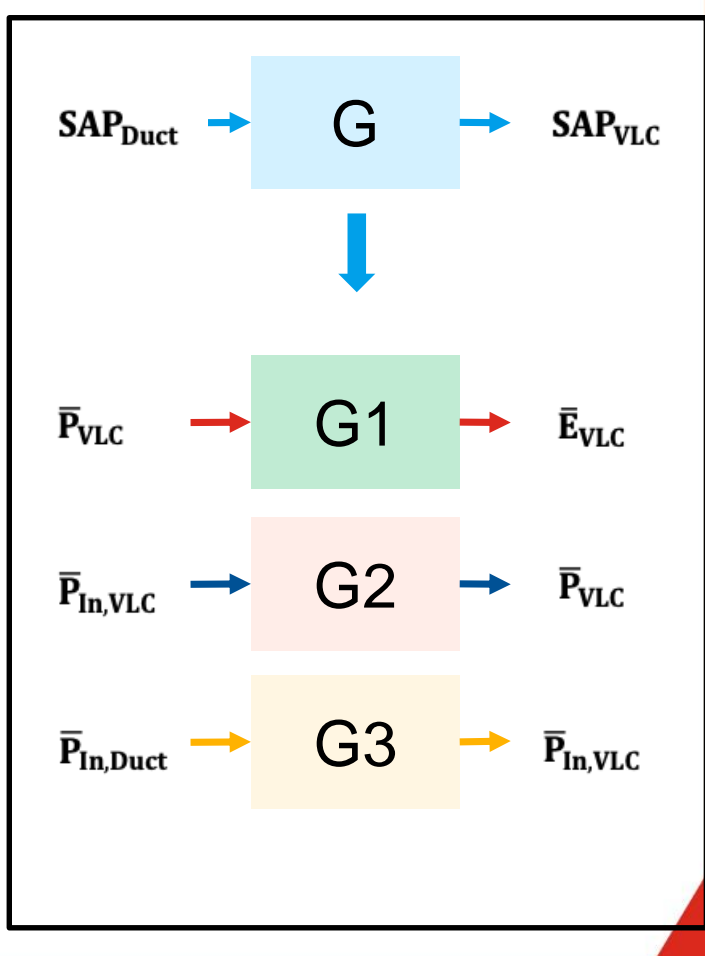




\section{EMPIRICAL EQUATION}

$$
\operatorname{SAP}_{\text {VLC }}=\frac{\overline{\mathbf{P}}_{\text {in,Duct }} \mathbf{A}_{\text {in,VLC }} \mathbf{A}_{\text {cavity,Duct }} \mathbf{F}_{1}\left(\overline{\boldsymbol{\alpha}}_{\text {VLC }}\right)}{\overline{\mathbf{P}}_{\text {Duct }} \mathbf{A}_{\text {cavity }, \text { VLC }} \mathbf{A}_{\text {in,Duct }} \mathbf{F}_{2}\left(\overline{\boldsymbol{\alpha}}_{\text {VLC }}\right) \mathbf{F}_{3}\left(\overline{\boldsymbol{\alpha}}_{\text {VLC }}\right)} \operatorname{SAP}_{\text {Duct }}
$$

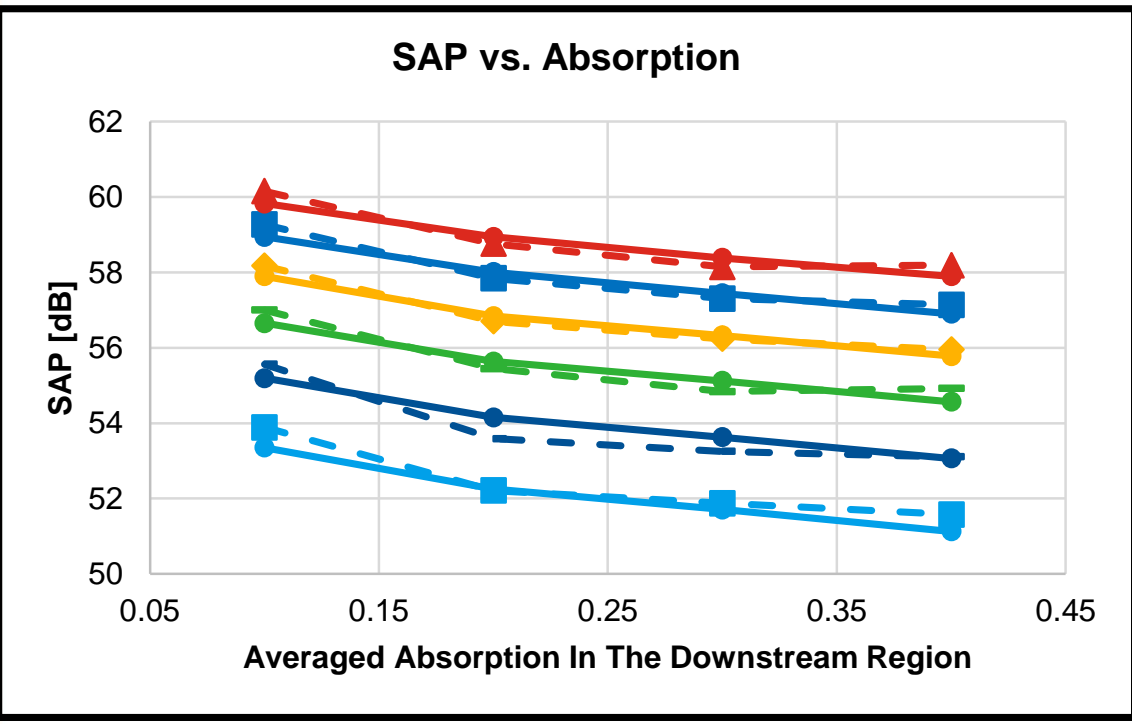

\begin{tabular}{|c|cccc|}
\hline \multicolumn{5}{|c|}{ SAP Error (\%) } \\
\hline & \multicolumn{5}{|c|}{ Absorption } \\
\hline SAP Target (dB) & 0.1 & 0.2 & 0.3 & 0.4 \\
\hline 56.3 & 1.01 & 0.08 & 0.32 & 0.88 \\
58.1 & 0.67 & 1.04 & 0.70 & 0.08 \\
59.6 & 0.62 & 0.34 & 0.51 & 0.64 \\
60.8 & 0.47 & 0.24 & 0.16 & 0.31 \\
61.9 & 0.56 & 0.28 & 0.24 & 0.42 \\
62.9 & 0.54 & 0.30 & 0.41 & 0.50 \\
\hline
\end{tabular}

ERROR $\%=\frac{\mathbf{A B S}\left(\mathbf{S A P}_{\mathrm{FEA}}-\mathbf{S A P}_{\text {Prediction }}\right)}{\text { SAP }_{\mathrm{FEA}}} * 100$

Dashed line: Prediction, Solid line: FEA results

(Target SAPs [dB] : Red $\rightarrow \mathbf{0 . 0 2 8}$, Blue $\rightarrow \mathbf{0 . 0 2 5}$, Yellow $\rightarrow \mathbf{0 . 0 2 2}$, Green $\rightarrow \mathbf{0 . 0 1 9}$, Navy $\rightarrow \mathbf{0 . 0 1 6}$, Sky blue $\rightarrow \mathbf{0 . 0 1 3}$ )

Desired target level in VLC can be related in this way to target level in simple duct geometry 


\section{EFFECT OF TARGET AREA}

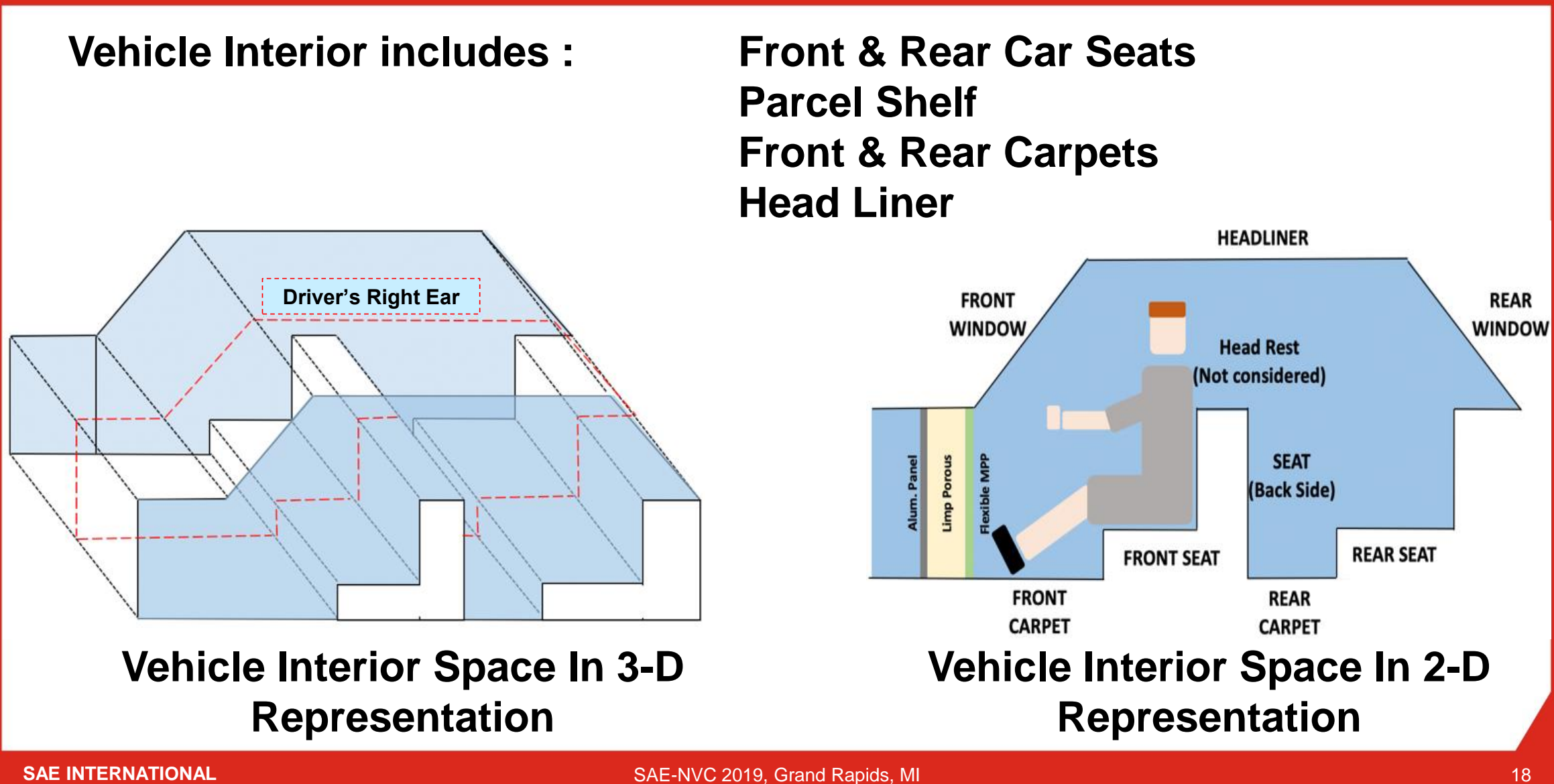




\section{EFFECT OF TARGET AREA}

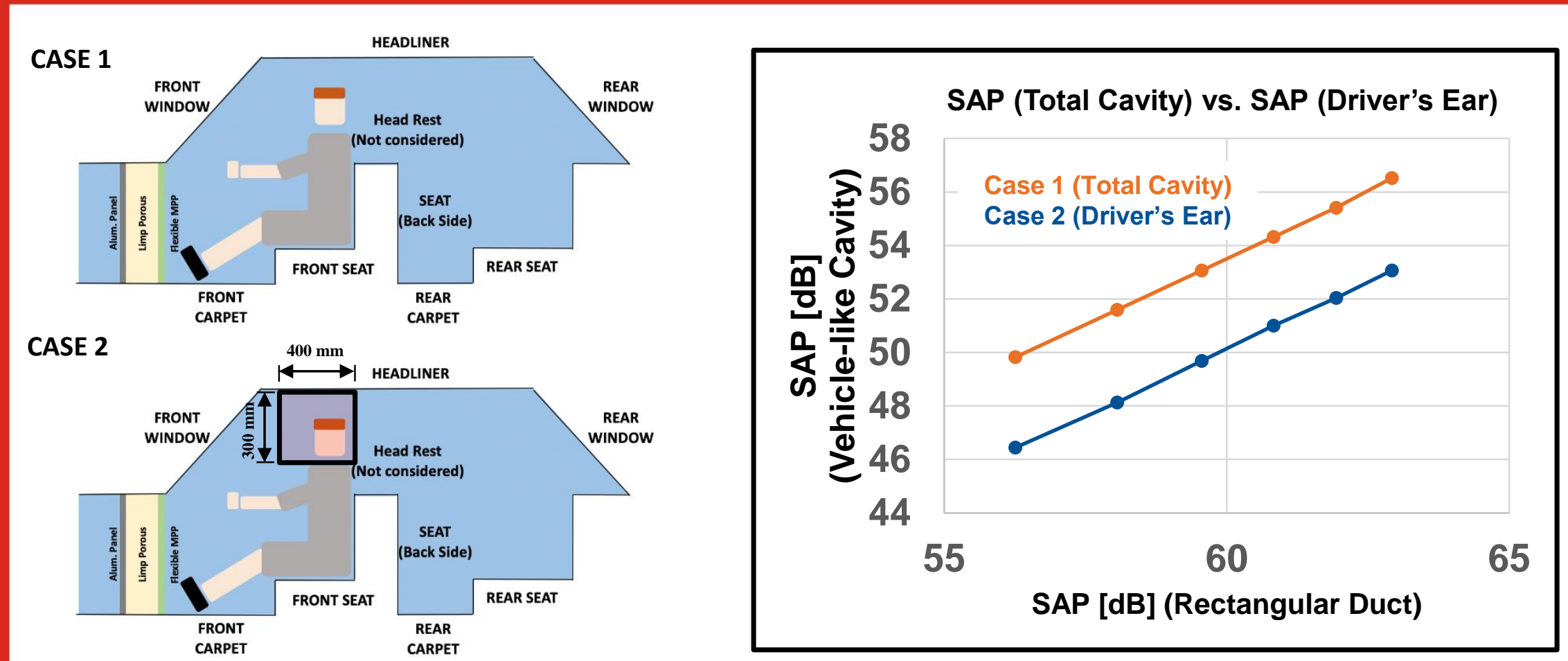

- Almost constant level difference in decibels between the two cases

- SAP of the total cavity of the vehicle interior can still be used as a metric to evaluate the acoustic performance of the sound packages, but with an adjustment to account for the spatial variation within the interior space. 


\section{CONCLUSIONS}

- The sound package was modeled as an equivalent fluid by using the JCA model for both the limp porous layer and the flexible MPP

- Genetic Algorithm was used to find the various sound package property combinations

- It was shown that in the lightest sound packages, barrier performance was favored over absorption performance

- When mass of the metal panel was increased, balance shifted towards absorption

- Shape and level of target spectrum has significant impact on required mass

- Finite Element tool was used to evaluate the acoustic performance of the sound packages for a more complex vehicle interior geometry. By using the FE tool, the energy density, SAPs, and incident power were calculated to study the correlation between the straight duct and the complex geometry cases

- An empirical equation was developed that makes it possible to estimate the SAPs in the complex geometry case by using the results from the TMM-based optimization in the straight duct case 
- The analysis needs to be extended to frequency-dependent impedances so that the accuracy of the SAP calculations can be further improved

- The empirical equation needs to be improved by implementing more exact correlation functions rather than the linearized functions used here to estimate the SAPs in the complex geometry

- Finally, it would be useful, given adequate computational resources, to extend the current procedure to three dimensions 


\section{Thank you}

- Hyunjun Shin

- Ray. W. Herrick Laboratories, Purdue University

- 177 S Russell st.

- shin20@purdue.edu

- Presentation available at Publication of the Ray W. Herrick Laboratories (Herrick E-Pubs) https://docs.lib.purdue.edu/herrick/ 


\section{Rate My Talk in the Mobile App}

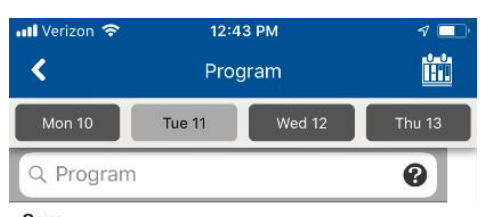

$8 a m$

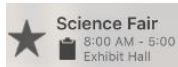

9am

Tuesday Keynote: Raymond Kach, Ford

$10 \mathrm{am}$

toeavy Duty Truck / Off-Highwa , >

Hybrid and Electric Vehicles (Part $\left.{ }^{2)}\right\rangle$

Instrumentation: Systems, Senso and

舟

1. Navigate to session listing under Program

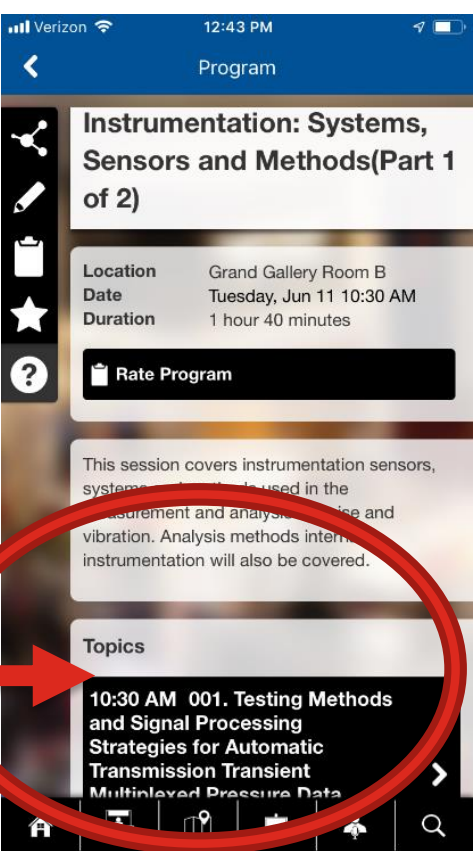

2. Click on individual presentation

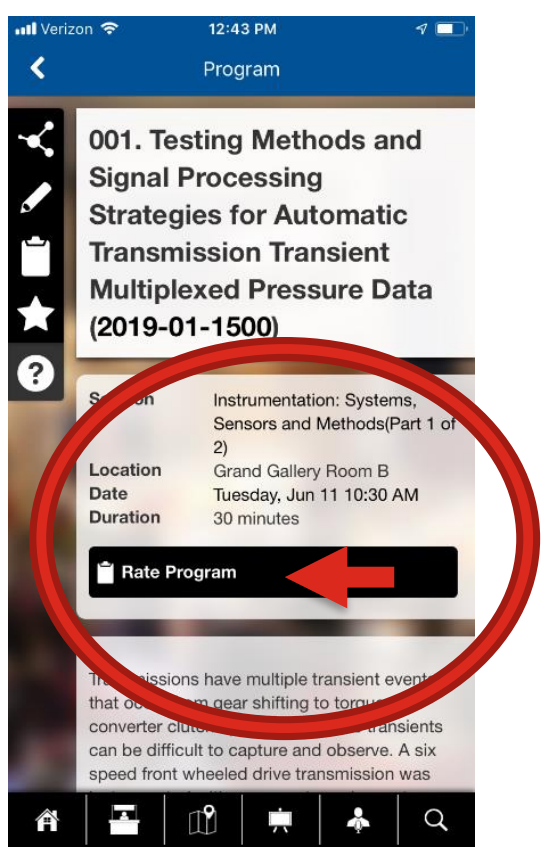

3. Click on "Share Feedback" button

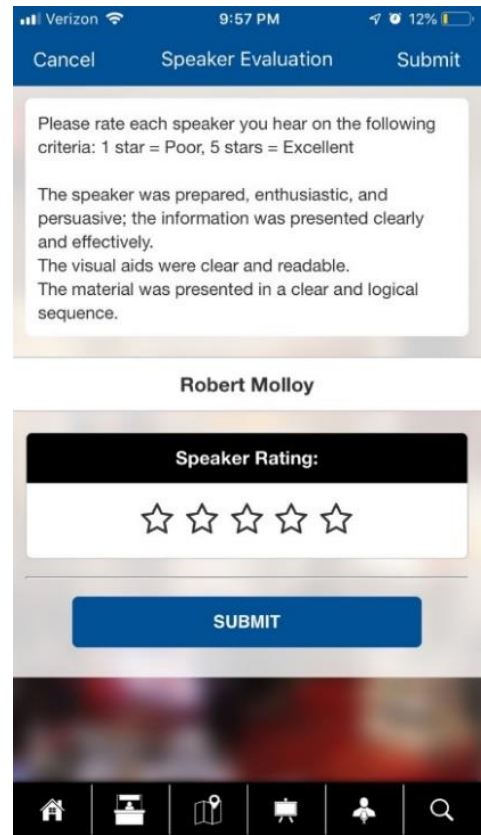

4. Rate speaker based on 3 criteria 